sum of money will be distributed in prizes for inventions and improvements of fishing gear; the special prizes in this department alone will number over Ioo, ranging in value from $600 l$. to $2 l$. IOs. Over $1000 l$. will also be given for essays on various topics connected with the economy of the fisheries and the natural history of our more important food fishes, as also for papers on fishery legislation. The dissemination of the knowledge to be obtained from such essays as may be awarded prizes is important. None of the essays contributed to the Norwich Exhibition have been published, except that of Sir James Maitland, printed presumably at his own expense, so that whatever information was contained in the Norwich prize essays remains only in the cognisance of those who read them. The Edinburgh prize essays are, we believe, being printed. Surely they might have been published ere this, and it might be taken into consideration by the executive of the present Exhibition, whether it is possible to have the essays judged, the prizes awarded, and a print of such as are worthy of being published on sale in the building in the course of the summer : a popular "handbook" to the Exposition will, we may presume, be issued. As to " exhibits" of a useful kind, such as those of fishing gear of every description, men with a practical turn of mind will be able to take stock of them and perceive at a glance how far they can be utilised. As a class, fishermen are slow to learn and chary in the way of trying experiments, but it is not impossible that the approaching Exhibition may contain the germs of some new ideas which may prove alike practical and profitable.

\section{THE PROGRESS OF TELEGRAPHY}

THE first of the series of six lectures on the Applications of Electricity was delivered on Thursday evening, February I 5, at the Institution of Civil Engineers, on "The Progress of Telegraphy," by Mr. W. H. Preece, F.R.S., M.Inst.C.E., of which the following is an abstract :-

Telegraphy is the oldest practical application of electricity. It grew about the railway system, and was rendered a practical agent by the foresight of Robert Stephenson, I. K. Brunel, Joseph Locke, and G. P. Bidder, who were its godfathers in England. Electric currents are, as a rule, maintained for telegraphic purposes by the combustion of zinc, and in the innumerable forms of batteries in use, the conversion of zinc into sulphate of zinc is the root of the transformation of energy into that form which was utilised as electric currents. There are three forms of battery in use in the British Post-Office Telegraph system, and in the following numbers :-

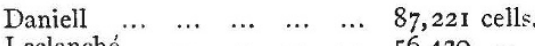

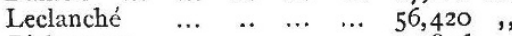

$$
\begin{aligned}
& \text { Bichromate } \quad \ldots \quad \ldots \quad \ldots \quad \ldots \quad 2 \mathrm{I}, 846 \text {, }
\end{aligned}
$$

Every administration has its own adopted form, differing in design, but based on one or other of these types. Magneto-electricity is employed for some forms of apparatus, and dynamo-machines are sometimes used to supplement batteries. Experiments are now being made with secondary ba'teries. The various terms employedelectromotive force, resistance, induction, and currentthough measurab'e in definite units, have not yet become household words; but, being admitted into commercial, legal, and Parliamentary lore, they will soon be as familiar as feet, gallons, or pounds.

Electric currents are conveyed from place to place either overground, underground, or submarine.

Ovenground.-Wooden poles preserved in creosote are employed in England, but iron poles are extensively used in the colonies. The conducting wire is almost universally of iron, but copper wire is much used through smoky places where iron is liable to rapid decay. Phosphor-bronze wire is under trial, and is a very promising material, as it possesses the conductivity of copper with the strength of iron. The improvements made in the quality of iron wire have been very great, and it conducts now fully 50 per cent. better than it did a few years ago. Electric tests have had a marvellous effect upon the production of pure metallic conductors; copper has improved in even greater ratio than iron; samples have been produced better even than the standard of purity. The insulators remain principally of porcelain, and their forms vary nearly with the number of individuals who use them; the only improvement of any value recently made is one which facilitates the very necessary process of cleaning.

Underground.--Wires are almost invariably carried underground through towns. Copper wire, insulated with gutta-percha, incased in iron pipes, is the material used. There are 12,000 miles of underground wire in the United Kingdom. There is a great outcry for more underground work in England, owing to the destruction to open lines by gales and snowstorms; but underground telegraphs, wire for wire, cost at present about four times as much as overground lines, and their capacity for the conveyance of messages is only one-fourth ; so that overground are, commercially, sixteen times better than underground wires. To lay the whole of the Post-Office system underground would mean an expenditure of about $20,000,000 l$. Hence there is no desire to put wires underground except in towns. Besides snowstorms are few and far between, and their effects are much exaggerated. of the numerous materials and compounds that have been used for insulating purposes, gutta-percha remains the oldest and the best for underground purposes. It, like all other materials used for telegraphy, has been improved vastly through the searching power that the current gives the engineer.

Submarine.-The past ten years has seen the globe covered with a network of cables. Submarine telegraphs have become a solid property. They are laid with facility and recovered with certainty, even in the deepest oceans. Thanks to such expeditions as that of H.M.S. Challenger, the floor of the ocean is becoming more familiar than the surface of many continents. There are at present 80,000 miles of cable at work, and $30,000,000 l$. have been embarked in their establishment. A fleet of twenty-nine ships is employed in laying, watching, and repairing the cables. The Atlantic is spanned by nine cables in working order. The type of cable used has been but very little varied from that first made and laid between Dover and Calais; but the character of the materials, the quality of the copper and the gutta-percha, the breaking strain of the homogeneous iron wire, which has reached go tons to the square inch, and the machinery for laying, have received such great advances, that the last cable laid across the Atlantic, by the Telegraph Construction and Maintenance Company, was done in twelve days without a hitch or stoppage.

Ideas are conveyed to the mind by electric signals, and in telegraphy these signals are produced at distant places by using two simple electrical effects: (I) that a magnetic needle tends to place itself at right angles to a wire when an electric current passes through it; and (2) that a piece of iron becomes a magnet when a current of electricity circulates around it. An innumerable quantity of tunes can be played on these two strings. Various companies were established at different times to work certain systems, but when the telegraphs were absorbed by the State the fittest were selected to survive, and their number consequently declined.

The A B C instrument is the simplest to read, for it indicates the letters of the alphabet by causing a pointer to dwell opposite the desired letter. There are 4398 in use. Its mechanism is, however, complicated and expensive, and it is being rapidly supplanted by the telephone. The needle instrument is the simplest in con- 
struction, but it requires training to work it. There are $379 \mathrm{I}$ in use in the Post Office, and 1 5,702 among different railway companies. As a railway instrument it is the simplest, cheapest, and most efficient ever devised. The Morse instrument, of which there are 1330 in use in the Post Office and 40,000 on the Continent, records its letters in ink, in dots and dashes on paper tape, and, like the needle and A B C, appeals to the consciousness through the eye; it also indicates the letters of the alphabet by sound, and thus utilises the organ of hearing. Soundreading is gaining ground in England with great rapidity. There are now 2000 sounders in use : in 1869 there were none. In America scarcely any other instrument is used. On the Continent there is scarcely one.

Acoustic reading attains great perfection in Bright's bell instrument, where beats of different sound replace the dot and dash of the Morse alphabet. Sound-reading is more rapid and more accurate than any system of visual signals or permanent record. In fact no record is kept in England, for the paper tape is now destroyed as soon as it has been read. Errors are of course inherent in all systems of telegraphy. A telegraphist cannot see what he writes, or hear what he says, and who is there that does not make mistakes whose eye follows his pen, or whose ear takes in his own words? The Hughes type-instrument, which prints messages in bold Roman characters, is much used on the Continent ; it is, in fact, recognised as the international instrument, but it has had to give way in England to a more rapid system of telegraphy. It is, however, solely used for the Continental circuits by the Submarine Telegraph Company. All long cables are worked by Sir William Thomson's beautiful siphon-recorder.

In ordinary working only one message can be sent in one direction at one time ; but by a simple and ingenious contrivance, by which the neutrality of opposite currents is utilised to convey signals, duplex telegraphy is rendered possible, so that two messages can be sent on the same wire at the same time; and by a still further improvement, where currents of different strength are utilised, four messages are sent on one wire-two simultaneously in opposite directions-at the same time. There are in England 319 duplex and i3 quadruplex circuits at work.

The acme of efficiency in telegraphy is attained in the automatic system, in which manual labour is supplanted by mechanism in transmitting the messages. There are $7 \mathrm{I}$ circuits worked by these instruments, and 224 instruments in use, and a speed of working of $2 \mathrm{co}$ words per minute is easily maintained upon them. When the hand alone is used, from 30 to 40 words fer minute is the maximum rate attained, but by automatic means the limit is scarcely known. Since this system can be duplexed, and in many cases is so, 400 words per minute on one wire are easily sent. By the use of high-speed repeaters, the length of circuit for automatic working is scarcely limited; it would be easy to send roo words per minute to India.

The growth of business since the telegraphs have been acquired by the State is enormous : 126,000 messages per week have grown to an average of 603,000 ; but the mileage of wire has not increased in anything like the same proportion, the excess of traffic having been provided for by the great improvements made in the working capacity of the apparatus. In 1873 , the average number of messages per mile of wire was 147 , it is now 256 . It is in press work that the greatest increase has taken place : 5000 words per day at the time of the Companies have grown to $934, \mathrm{r} 54$ words per day now. 340,966,344 words of press matter were delivered in the year ending March 31,1882 .

The development of railways has necessitated a corresponding increase in the telegraphs required to insure the safety of the travelling public, and while 27,000 miles of wire in England, Scotland, and Wales were used for that purpose in 1869 , at the end of December, I882, the total had increased to 69,000 miles, equipped with 43,176 instruments, against 8678 in 1869 .

The growth of business is equally discernible in the great cable companies. In 1871 the number of messages dealt with by the Eastern Telegraph Company was 186,000 ; in 1881 , it was 720,000 . This growth is equally striking in all civilised countries, and even in Japan $2,223,214$ messages were despatched last year, of which 98 per cent. were in the native tongue. The mode of transacting the trade of the world has been revolutionised, and while wars have been rendered less possible, their conduct has been expedited, and their penalties alleviated.

\section{CENTRAL AND WEST AFRICA 1}

THE brilliant journey of Major Serpa Pinto across Africa from Loanda, by the Zambesi to Natal, must be fresh in the recollection of our readers. The present narrative may be regarded as complementary of the major's exciting story. Captains Capello and Ivens were members of the original expedition along with Major Pinto, and for the first part of the journey the three companions worked together. The object of the expedition, which was organised by the Portuguese (iovernment, was to thoroughly survey the great artery which-a tributary of the Congo-runs from south to north between $17^{\circ}$ and $19^{\circ} \mathrm{E}$. of Greenwich, and is known as the Cuango, as also to determine all the geographical bearings between that river and the west coast, and make a comparative survey of the hydrographical basins of the Congo and Zambesi. The three travellers started from Benguelia in November, 1877 , but had not proceeded far on their journey, when a difference of opinion arose as to the future route of the expedition. Messrs. Capello and Ivens did not feel at liberty to depart from the original letter of their instructions, while the bold Major Pinto conceived that he would be carrying out the spirit of their instructions by making a dash across the continent. We have nothing to do with the quarrels of the travellers; experience proves that in such an expedition there should be one supreme head, and that the best exploring work has often been done by a white traveller single-handed. Major Pinto's presence with the other two was really unnecessary, and it was certainly to the advancement of geographical knowledge that he took an entirely different route. Messis. Capello and Ivens are evidently two pleasant and agreeable gentlemen, though we have some doubts if exploration is exactly the mótier to which they are best adapted. At all events they have written a narrative that contains much pleasant reading, and some additions to our knowledge of the geography and natural history of the limited region which they traversed. Their real work lasted for about two years, during which they traced the Cuango northwards to about $5^{\circ} \mathrm{S}$. lat., when they were compelled to turn back, partly owing to the exhaustion of their supplies, and partly to the arid nature of the country beyond their farthest point. During their journey they crossed innumerable streams, some of them adding their waters to the Cuango and others joining the Cuanza, which discharges into the Atlantic south of Loanda. The sources of the Cunene, Cuanza, and Cuango were visited and determined, and a pretty careful survey of the region all along the route made. The country traversed is mostly mountainous, cut up by innumerable streams and valleys, rich in many parts in vegetation, and even in metals, and having a considerable population clustered in villages, each of which is ruled by its chief. With each of these chiefs much diplomacy had to be used in order that the

\footnotetext{
I "From Benguella to the Territory of Yacca; description of a journey by Alired Elwes, Ph.D. Two vols. (London: Sampson Low and Co.

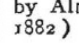

